\title{
The effects of parafoveal word frequency and segmentation on saccade targeting during Chinese reading
}

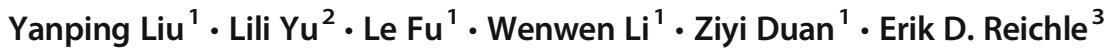

Published online: 1 March 2019

(C) The Psychonomic Society, Inc. 2019

\begin{abstract}
Two eye-movement experiments are reported in which a boundary paradigm was used to manipulate the presence versus absence of boundaries for high-frequency and low-frequency target words in the parafovea. In Experiment 1, this was done by introducing a blank space after the target words, whereas in Experiment 2 this was done by rendering the target words in red. In both experiments, higher frequency targets engendered longer saccades, whereas the presence of parafoveal word boundaries engendered shorter saccades. This pattern suggests the operation of two countermanding saccade-targeting mechanisms: one that uses parafoveal processing difficulty to adjust saccade lengths and a second that uses word boundaries to direct the eyes toward specific saccade targets. The implications of these findings for models of eye-movement control during reading are discussed, as are suggestions for integrating dynamic-adjustment and default-targeting accounts.
\end{abstract}

Keywords Chinese reading $\cdot$ Dynamic-adjustment model $\cdot$ Eye-movement control $\cdot$ Word segmentation

Skilled reading requires the coordination of lexical processing with eye movements to rapidly extract visual information from the printed page. One important aspect of this coordination is saccade targeting, or the "decisions" about where to move the eyes. Because much of what has been learned about eyemovement control in reading has come from studies involving alphabetic writing systems, models of how readers decide where to move their eyes have been informed largely by what has been learned from studying languages like English and German, where the eyes seem to be directed toward a small number of default targets (e.g., see Engbert, Nuthmann, Ricter, \& Kliegl, 2005; Reichle, Pollatsek, \& Rayner, 2012). For example, with English, readers seem to direct their eyes slightly to the left of a word's center, toward the preferred-viewing location (PVL;

Yanping Liu

liuyp33@mail.sysu.edu.cn

1 Department of Psychology, Guangdong Provincial Key Laboratory of Social Cognitive Neuroscience and Mental Health, Sun Yat-sen University, No. 135, Xingang Xi Road, Guangzhou 510275, People's Republic of China

2 Department of Cognitive Science, Macquarie University, Balaclava Road, North Ryde, NSW 2019, Sydney, Australia

3 Department of Psychology, Macquarie University, Balaclava Road, North Ryde, NSW 2019, Sydney, Australia
Rayner, 1979) because it supports efficient lexical processing (Rayner \& Morrison, 1981). This default-targeting account provides a simple, feasible explanation of the PVL because, in English, the blank spaces between words can be used to select saccade targets.

This account fares less well explaining eye movements if the spaces between words are removed (Rayner, Fischer, \& Pollatsek, 1998) or in writing systems that do not demarcate word boundaries. In written Chinese, for example, most words are composed of one to four uniformly sized characters that are written in continuous lines, without spaces between words (see Yu \& Reichle, 2017). Because of the absence of spaces, the fixationlocation distributions on Chinese words tend to be uniform, without clear PVLs (e.g., see Fig. 8.1, Tsai \& McConkie, 2003).

To provide a better understanding of saccade targeting in Chinese, Yan, Kliegl, Richter, Nuthmann, and Shu (2010) reported an eye-movement study suggesting that PVLs exist but vary as a function of how many times a word is fixated. Their analyses showed that words fixated exactly once tended to be fixated near their centers, but that words fixated twice or more tended to be fixated first near their beginnings and then somewhere further into the words. Their explanation of this pattern is that it reflects the segmentation of parafoveal words from continuous lines of characters: Words that are successfully segmented tend to be the recipients of a single fixation near their centers because this affords efficient lexical 
processing, whereas words that fail to be segmented tend to be the recipients of an initial fixation near the beginning followed by a subsequent fixation because this behavior minimizes the chances of having to disrupt the progress of the eyes through the text. Yan et al.'s account thus extend the default-targeting hypothesis by specifying how the parafoveal segmentation of upcoming words affects which of two possible default saccade targets might be selected. ${ }^{1}$ Finally, by replacing the traditional assumption that readers used low spatial-frequency information corresponding to word boundaries to guide eyes in spaced languages like English, Yan et al.'s provided a Chinese version of default-targeting hypothesis.

One limitation of the preceding account, however, is that it is based on correlational evidence. This was most clearly demonstrated by Li, Liu, and Rayner (2011) using a simulation in which saccade length was a constant with some random variability: Words that happened to be fixated near their centers also tended to be fixated only once, whereas words that happened to be fixed near their beginnings tended to be fixated multiple times. Another limitation of the default-targeting account is that it fails to explain why-even in languages with clear word boundaries, like English-lexical processing modulates saccade length. For example, the lengths of saccades exiting words are modulated by their frequency, with common words being followed by longer saccades (e.g., Rayner, Ashby, Pollatsek, \& Reichle, 2004; White \& Liversedge, 2006). Similar findings have also been reported with Chinese (e.g., Wei, Li, \& Pollatsek, 2013).

The above limitations of the default-targeting account led to the development of an alternative account in which saccade length is adjusted as a function of parafoveal processing difficulty (Y. Liu, Reichle, \& Li, 2015, 2016; cf. Wei et al., 2013). ${ }^{2}$ This dynamic-adjustment account maintains that variables affecting parafoveal processing difficulty also affect saccade length. To date, eye-movement experiments have shown these variables include the frequency of a fixated word (e.g., Liu, Huang, Gao, \& Reichle, 2017; Y. Liu et al., 2015), as well as the frequency (Y. Liu et al., 2016) and predictability (Liu, Guo, Yu, \& Reichle, 2018) of parafoveal words, and cues about their boundaries (Yan \& Kliegl, 2016; Zhou, Wang, Shu, Kliegl, \& Yan, 2018). Thus, with all else being

\footnotetext{
${ }^{1}$ Although Yan et al.'s (2010) self-described “flexible saccade-target selection" account allows Chinese readers to "dynamically select the beginning or center of words as saccade targets" (p.705), the eyes are only directed toward a few possible saccade targets. Therefore, to avoid confusion with a dynamic-adjustment account that posits no default targets, we use "defaulttargeting" when referring to Yan et al.'s (2010) explanation.

2 To explain the finding that difficulty associated with processing the fixated region affects outgoing saccade length, Wei et al. (2013) proposed a processing-based strategy in which readers of Chinese "estimate how many characters they can process on each fixation, and then program their next saccade so that the eyes fixate somewhere beyond them" (p. 1). However, because this strategy is "blind to the physical word boundaries" (p. 6), it is unclear how it could explain our results showing that the introduction of word boundaries influences saccadic targeting.
}

equal, variables that facilitate the parafoveal word processing tend to increase saccade lengths into those words.

Such demonstrations motivated the development of computationally explicit versions of the two saccade-targeting accounts, which were used to simulate the eye-movement data from several of the aforementioned experiments (Liu et al., 2018; Liu et al., 2017; Y. Liu et al., 2016). The results of those simulations have consistently shown that the dynamic-adjustment model provides a better quantitative fit of the data using fewer free parameters. However, despite these successes, it has always been acknowledged that a full account of saccade-targeting during reading will likely entail elements of both saccade-length adjustment and default-target selection (e.g., Y. Liu, Yu, \& Reichle, 2019). Although such an account will not be provided in this article, the experiments reported below provide the first direct evidence of both saccade-targeting mechanisms in the context of a single experimental paradigm.

As described below, the frequency of target words was manipulated to control the relative ease of lexical processing (Rayner et al., 2004). Additionally, the boundary paradigm (Rayner, 1975) was used to manipulate the availability of their boundaries by either introducing a blank space after the targets (Experiment 1) or rendering the targets in red (Experiment 2) during preview. The two saccade-targeting hypotheses make opposite predictions: According to a strong version of the dynamic-adjustment hypothesis, target words that are high frequency or have clear boundaries should engender longer saccades because they are easier to process, while according to a strong version of the default-targeting hypothesis, such targets should increase the probability of the eyes being directed towards the centers of the targets because they are easier to segment. Of course, a hybrid account might predict that our manipulations differentially affect where the eyes move (e.g., see Hyönä, Yan, \& Vainio, 2018) — a possibility that was also tested by the experiments reported next.

\section{Experiment 1}

\section{Method}

Participants Forty native Chinese-speaking undergraduates (26 females; mean age $=19.63$ years) with normal or corrected-to-normal vision from Sun Yat-sen University were paid 20 yuan to participate the experiment. All participants were instructed to read sentences for comprehension and gave written consent prior to the experiment.

Apparatus An EyeLink 1000+ Tower-Mounted Eye-Tracking system (SR Research, Ltd.) with a $1000-\mathrm{Hz}$ sampling rate recorded readers' eye movements. Participants were seated approximately $58 \mathrm{~cm}$ from a 27-in. LED display monitor (ASUS; PG27AQ; resolution $=2560 \times 1440$ pixels; $144-\mathrm{Hz}$ 
refresh rate). Sentences were presented in white Song font, centered vertically of a black background, with each character occupying a $40 \times 40$-pixel grid $\left(\sim 1^{\circ}\right.$ of visual angle) .

Materials and experimental design 172 pairs of two-character target words of either high $(M=111.44$ per million, $S D=73.77)$ or low $(M=2.15$ per million, $S D=1.42)$ frequency of occurrence were embedded near the center of the same sentence frames (see Fig. 1). Character frequency and target-word complexity (i.e., number of strokes) were also controlled between conditions (all $p$ s > 0.100; see Table 1). Target word predictability was then estimated by asking an independent sample of 16 Chinese participants to predict the target words from their preceding sentence context; there was no significant difference between the high- and low-frequency conditions ( $t=$ $1.51, p=0.132)$. Another 16 participants were asked to assess the naturalness of the sentences, with no difference between the conditions $(t=-1.64, p=0.115)$. As mentioned above, in the segmentation-preview condition, target-word preview was manipulated using a gaze-contingent boundary paradigm (Rayner, 1975) by inserting a blank space after the target word that disappeared after the eyes crossed an invisible boundary (see Fig. 1). The experiment used a counterbalanced design to ensure that each participant read each sentence frame only once and read the same number of sentences per condition.

Procedure The eye tracker was first calibrated and validated using a 3-point procedure. Each trial began with a drift check at the center of the screen. A $1^{\circ} \times 1^{\circ}$ white box (to check calibration) was then displayed at the first character position of the sentence until it was fixated. If the box was not fixed or the drift check produced an error in excess of $0.4^{\circ}$, then the participant was recalibrated. Reading was binocular, but only the movement of the right eye was recorded. Participants were instructed to read silently. Each participant first read 15 practice sentences, and then read the 172 experimental sentences in a random order. Participants pressed response buttons to terminate sentence reading, answer comprehension questions (after half of the total sentences), and start each trial.

\section{Results}

Data preparation Trials containing blinks immediately before, on, or immediately after the target words were removed from analyses, as were trials in which display changes were triggered prematurely or completed $\geq 10 \mathrm{~ms}$ after the subsequent fixation to avoid eye-movement disruptions. Data more than three standard deviations from a condition mean were also excluded. Approximately $10.14 \%$ of the trials were excluded using these criteria.

Comprehension accuracy Ninety-three percent of the comprehension questions were answered correctly on average, with no significant differences among word-frequency and segmentation-preview conditions (all $p \mathrm{~s}>.10$ ).

Eye-movement measures Because our primary analyses examined how target-word frequency and segmentation-preview affected saccade targeting, we report two saccade-length measures: (1) progressive-saccade length (PSL), or mean amplitude of initial saccades launched from the pretarget region, irrespective of whether they resulted in target-word fixations; and (2) incomingsaccade length (ISL), or subset of progressive saccades that resulted in target-word fixations. To facilitate the comparison with the literature, we also report (3) landing position, or mean position of the first target-word fixations; and (4) skipping probability, or mean probability of not fixating the target words during first-pass reading. To control for any potential confounds caused by the limitations of the perceptual span (which extends two to three characters to the right of fixation; e.g., Chen \& Tang, 1998), our analyses of the aforementioned measures were restricted to saccades launched from the two-character pretarget region. Finally, to examine how target-word frequency and segmentation-preview affected lexical processing, we also report (5) first-fixation duration (FFD), or the mean duration of the initial target-word fixation during first-pass reading; and (6) gaze duration (GD), or the mean sum of all first-pass target-word fixation durations.

Each measure was fitted using linear mixed-effect models (or a generalized linear mixed-effect model for skipping probabilities), using target-word frequency and segmentationpreview conditions as design factors (coded as sum contrasts: 0.5 vs. -0.5 for high-frequency vs. low-frequency, and for segmented vs. unsegmented previews). For each dependent variable, the intercept thus estimates the grand mean across conditions and the regression coefficients estimate the differences between factor levels. Saccade launch sites were also added as a covariate for saccade-related measures. To improve the generalizability of our analyses, all models used the maximal random-effects structure. The random-effects structures in the models thus have appropriate variance and covariance components due to participants, items, and saccade launch sites, and different slopes for each predictor for each covariant. Models and their $p$ values were respectively fitted using the lme 4 and lmerTest packages in $\mathrm{R}$ (Version 3.5.1).

As shown in Figs. 2 and 3 (means) and Table 2 (linear mixed-effect models), PSL was longer for high-frequency than for low-frequency target words $(p<.001)$. ISL also showed the same numerical tendency, but this trend was not significant $(p=.290){ }^{3}$ However, segmentation-preview differentially influenced the two saccade-targeting measures:

\footnotetext{
${ }^{3}$ This lack of significance likely reflects the fact that there were fewer incoming saccades (which are a subset of progressive saccades). However, the wordfrequency effect on ISL was significant both using anti-conservative methods (e.g., removing the random target-word frequency slopes for each subject and item; $p<.05)$ and in Experiment 2.
} 
a

$\begin{array}{ll}\text { HF-UP: } & \text { 中国学生从英国朋友那里学会了圣诞歌谣。 } \\ & \text { 中国学生从英国朋友那里学会了圣诞歌谣。 } \\ \text { HF-SP: } & \text { 中国学生从英国朋友 那里学会了圣诞歌谣。 } \\ & \text { 中国学生从英国朋友那里学会了圣诞歌谣。 } \\ & \text { (The Chinese students have learned a Christmas song from the British friends.) } \\ \text { LF-UP: } & \text { 中国学生从英国访客那里学会了圣诞歌谣。 } \\ & \text { 中国学生从英国访客那里学会了圣诞歌谣。 } \\ & \text { 中国学生从英国访客 那里学会了圣诞歌谣。 } \\ & \text { 中国学生从英国访客那里学会了圣诞歌谣。 }\end{array}$

b

HF-UP:

中国学生从英国|朋友那里学会了圣诞歌谣。 中国学生从英国鹏友那里学会了圣诞歌谣。

HF-SP: 中国学生从英国朋友那里学会了圣诞歌谣。 中国学生从英国朋友那里学会了圣诞歌谣。

(The Chinese students have learned a Christmas song from the British friends.) I

LF-UP: 中国学生从英国访客那里学会了圣诞歌谣。 中国学生从英国访客那里学会了圣诞歌谣。 1

Fig. 1 Examples of the Chinese sentences (and their English translations) and the gaze-contingent boundary paradigm used in Experiments 1 and 2 to manipulate the parafoveal segmentation of target words. In Experiment 1 (a), segmentation was manipulated by introducing a blank space after the target, whereas in Experiment 2 (b), segmentation was manipulated

PSL was longer for segmented than unsegmented previews ( $p$ $<.001)$, whereas ISL was shorter for segmented than unsegmented previews $(p=.002)$. Consistent with the latter, landing position was further to the left in the segmented than unsegmented preview $(p=.002)$. There was no significant interaction between target-word frequency and segmentation on ISL ( $p=.944)$, but this interaction was significant for PSL, with larger word-frequency effects for segmented than unsegmented previews $(p=.011)$. As Fig. 3 shows, saccade launch site also affected saccade length: From launch sites closer to the using font color. In both panels, the dashed lines represent the invisible boundary that, after the eyes cross it, cause the segmentation cues to disappear. Note. $\mathrm{HF}=$ high frequency; $\mathrm{LF}=$ low frequency; $\mathrm{UP}=$ unsegmented preview; $\mathrm{SP}=$ segmented preview

target words, PSL increased ( $p=.027)$, but ISL decreased $(p<$ .001 ). Additionally, because the slope of the relationship between launch site and landing site was less than one, the landing position on the target word actually shifted to the right for launch sites closer to the target word $(p<.001) .{ }^{4}$ Finally, high-

\footnotetext{
${ }^{4}$ This finding is counterintuitive but can be understood as follows: As the saccade launch site on average moves one character space closer to the target word, the ISL increases by approximately a third of a character space, thereby causing the overall ISL to decrease, but the landing position on the target word to shift to the right.
} 
Table 1 Stimulus properties in Experiments 1 and 2

\begin{tabular}{|c|c|c|c|c|c|}
\hline \multirow[t]{2}{*}{ Properties } & & \multicolumn{2}{|l|}{ Conditions } & \multirow[t]{2}{*}{$t$} & \multirow[t]{2}{*}{$p$} \\
\hline & & Low frequency & High frequency & & \\
\hline \multirow[t]{5}{*}{ Target words } & $\begin{array}{l}\text { Word frequency } \\
\text { (counts per million) }\end{array}$ & $\begin{array}{l}2.15 \\
(1.42)\end{array}$ & $\begin{array}{l}111.44 \\
(73.77)\end{array}$ & 19.33 & $<.001$ \\
\hline & $\begin{array}{l}\text { First character frequency } \\
\text { (counts per million) }\end{array}$ & $\begin{array}{l}751.97 \\
(1058.31)\end{array}$ & $\begin{array}{l}905.67 \\
(823.38)\end{array}$ & 1.43 & .154 \\
\hline & $\begin{array}{l}\text { Second character frequency } \\
\text { (per million) }\end{array}$ & $\begin{array}{l}802.29 \\
(1107.15)\end{array}$ & $\begin{array}{l}938.85 \\
(781.63)\end{array}$ & 1.38 & .171 \\
\hline & $\begin{array}{l}\text { First character complexity } \\
\text { (number of strokes) }\end{array}$ & $\begin{array}{l}8.88 \\
(3.15)\end{array}$ & $\begin{array}{l}8.37 \\
(2.63)\end{array}$ & 1.63 & .106 \\
\hline & $\begin{array}{l}\text { Second character complexity } \\
\text { (number of strokes) }\end{array}$ & $\begin{array}{l}8.65 \\
(3.10)\end{array}$ & $\begin{array}{l}8.24 \\
(2.48)\end{array}$ & 1.42 & .158 \\
\hline \multirow[t]{2}{*}{ Sentences } & Predictability & $\begin{array}{l}0.004 \\
(0.02)\end{array}$ & $\begin{array}{l}0.01 \\
(0.03)\end{array}$ & 1.51 & .132 \\
\hline & Naturalness & $\begin{array}{l}3.84 \\
(0.37)\end{array}$ & $\begin{array}{l}3.74 \\
(0.46)\end{array}$ & -1.64 & .115 \\
\hline
\end{tabular}

Note. The $t$ tests are between high-frequency and low-frequency target-word conditions

frequency targets were skipped more than low-frequency targets $(p<.001)$, and fixation-duration measures were similarly influenced by the ease of target-word processing (see Fig. 4): FFDs and GDs were shorter on high-frequency than on lowfrequency targets (FFD: $p=.004$; GD: $p<.001$ ), and likewise shorter with segmented than unsegmented previews (FFD: $p<$ .001 ; GD: $p<.001)$.

Interim discussion Experiment 1 manipulated both the frequency and parafoveal segmentation of target words, the latter by inserting a blank space after target words prior to them being fixated. Apart from replicating the standard wordfrequency effect (e.g., see Schilling, Rayner, \& Chumbley, 1998), our results suggest two countermanding tendencies that, by our interpretation, correspond to two modes of "deciding" where to move the eyes during reading. The first is that saccades into high-frequency words tended to be longer than those into low-frequency words, suggesting that readers are sensitive to parafoveal processing difficulty and adjust their saccade lengths accordingly. The second is that the introduction of a cue to facilitate the segmentation of a parafoveal word actually reduced saccade length — at least in those instances where the target words were subsequently fixated (i.e., using the ISL measure). This second finding suggests that if information about word boundaries is provided, it can be used by the oculomotor system to constrain the choice of possible saccade targets, thereby allowing the eyes to be directed more toward the centers of words. Our first experiment, therefore, provides tentative evidence for both the dynamic adjustment of saccade length and the use of default saccade targets within a single paradigm. One possible limitation of this interpretation, however, is our finding that targetword segmentation did not shorten saccades as measured using PSL. This lack of consistency between our two measures may reflect the fact that our parafoveal manipulation of target-word segmentation was weak. To test this hypothesis and possibly provide further support for our claim of having identified two bases for saccade targeting, we conducted an experiment in which target boundaries were made more salient by manipulating the font color of its preview (see Fig. 1).

\section{Experiment 2}

\section{Method}

Participants Thirty university students (20 females; mean age $=20.47$ years) from Sun Yat-sen University were recruited to participate. All participants had normal or corrected-to-normal vision and no problems with color vision.

Apparatus The eye tracker was identical to that used in Experiment 1.

Materials and experimental design As shown in Fig. 1, the only difference between Experiments 1 and 2 was that, in the latter, rather than segmenting the target-word preview by introducing a blank space after the target, the target was segmented by either rendering it or it and all subsequent characters red during the preview (i.e., prior to the eyes crossing the invisible display-change boundary).

Procedure The procedure was identical to that in Experiment 1. 


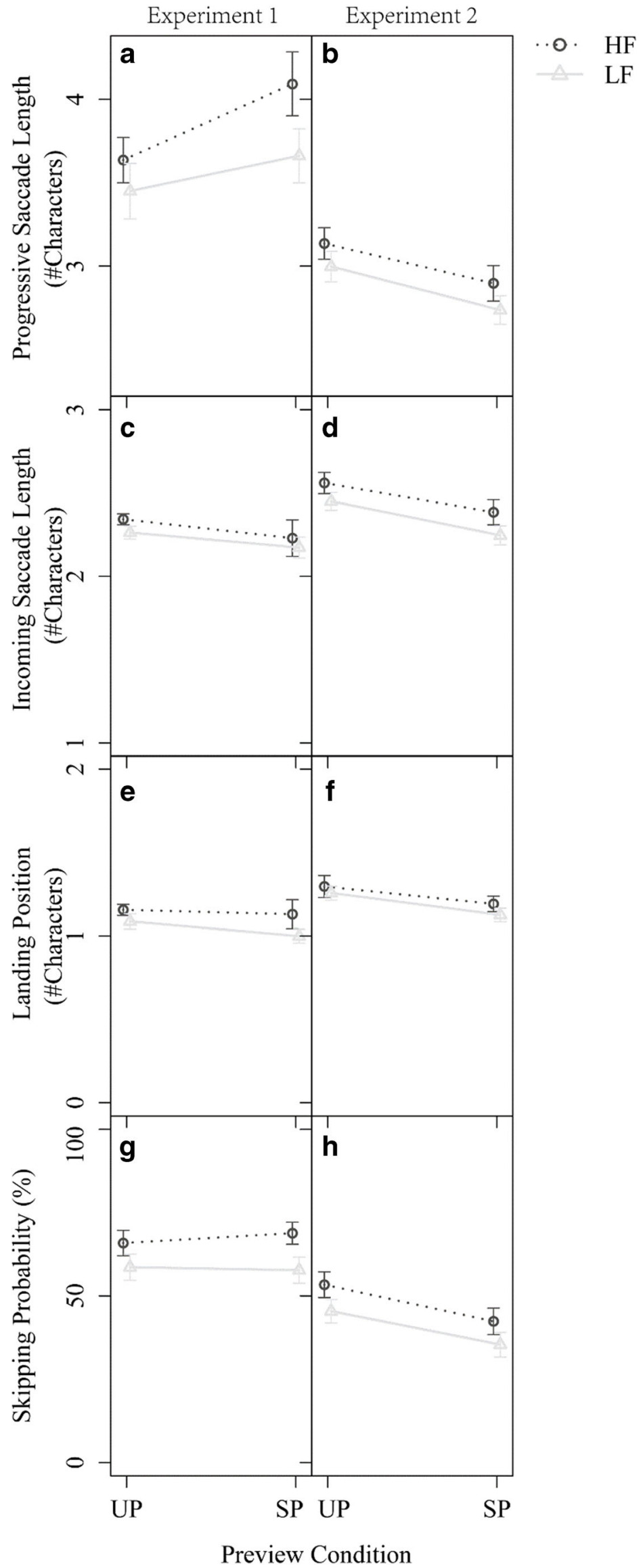


Fig. 2 Mean saccade-length measures from Experiments 1 (left panels) and 2 (right panels). Note. $\mathrm{HF}=$ high frequency; $\mathrm{LF}=$ low frequency; UP = unsegmented preview; $\mathrm{SP}=$ segmented preview

\section{Results}

Data preparation The data extraction criteria were identical to those used in Experiment 1, resulting in $13.06 \%$ of the trials being excluded from our analyses.

Comprehension accuracy Participants correctly answered $97 \%$ of the comprehension questions, with no differences among word-frequency and segmentation-preview conditions (all $p$ s > .10).

Eye-movement measures As Figs. 2 and 3 (means) and Table 2 (linear mixed-effect models) show, PSL and ISL were longer for high-frequency than for low-frequency target words (PSL: $p=$ .043; ISL: $p=.022$ ), causing landing positions to be further to the right for high-frequency than for low-frequency target words $(p<$ .001). However, both measures were shorter for segmented than unsegmented previews (PSL: $p<.001$; ISL: $p<.001$ ), which resulted in the landing position being further to the left for segmented than unsegmented previews $(p<.001)$. And for launch sites closer to the target words, ISL decreased $(p<.001)$ and the landing position shifted to the right $(p<.001$; see footnote 4); PSL showed the same numerical tendency but failed to reached significance $(p=.170)$. Finally, high-frequency targets elicited more skipping than did low-frequency targets $(p=.003)$, but segmented previews elicited less skipping than did unsegmented previews $(p<.001)$. And similar to Experiment 1 (see Fig. 3), fixation-duration measures were shorter on highfrequency than low-frequency targets (FFD: $p<.001$; GD: $p=$ $.008)$, as well as for segmented than unsegmented previews (FFD: $p=.002$; GD: $p<.001$ ).

Interim discussion Experiment 1 provided cursory but inconsistent evidence for two saccade-targeting mechanisms — one based on the selection of default targets and a second based on the dynamic adjustment of saccade length. Experiment 2 was designed to provide further support for this conclusion by employing a stronger manipulation of parafoveal word segmentation - the demarcation of target-word boundaries using font color. As predicted, this manipulation, in conjunction with our manipulation of target-word frequency, revealed two countermanding tendencies. The first was for target-word

Experiment 1

Experiment 2

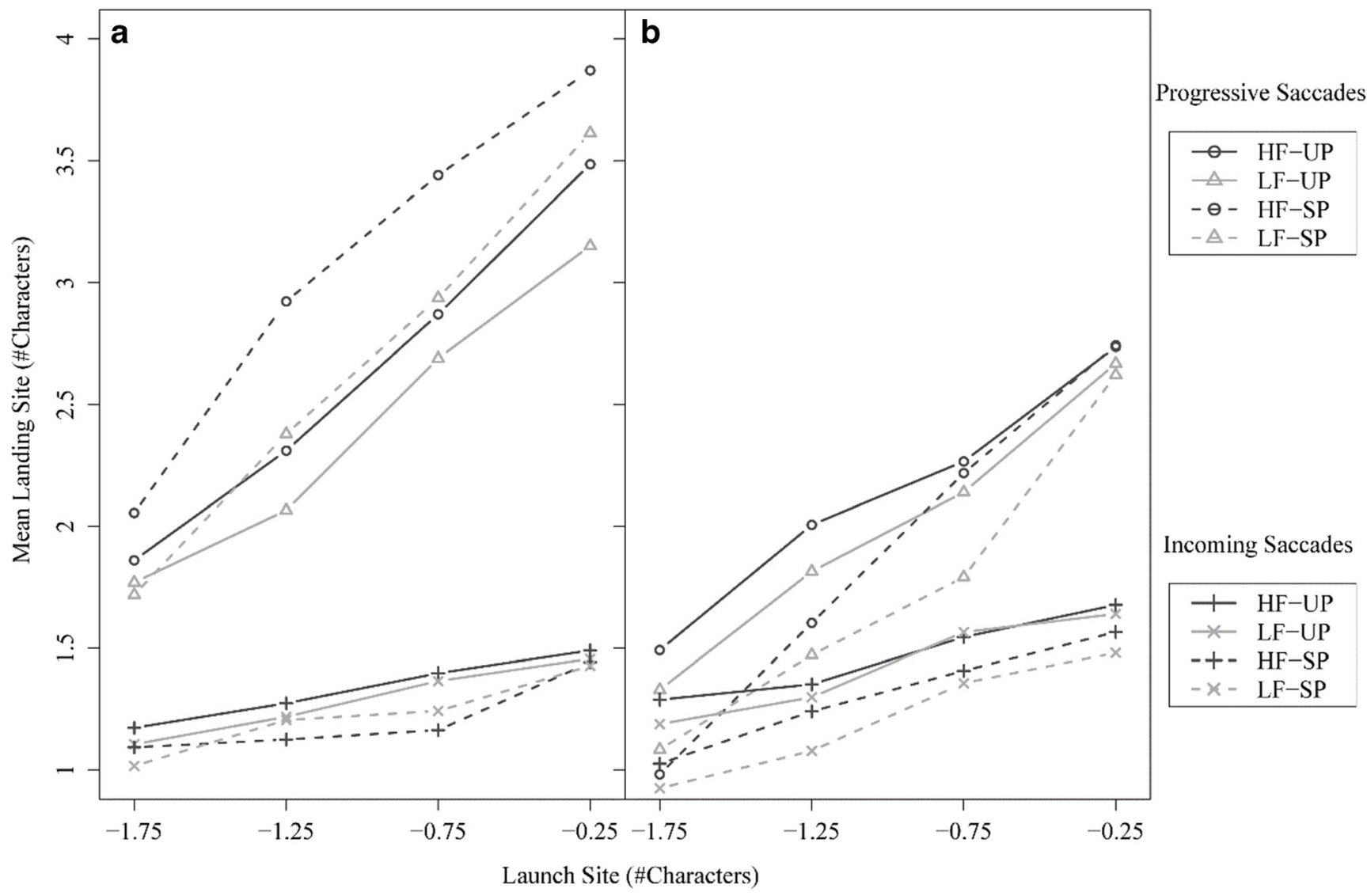

Fig. 3 Relationship between the saccade launch site and the subsequent fixation landing site (in character spaces) in Experiments 1 (a) and 2 (b). Note. $\mathrm{HF}=$ high frequency; $\mathrm{LF}=$ low frequency; $\mathrm{UP}=$ unsegmented preview; $\mathrm{SP}=$ segmented preview 
Table 2 LMM inferential statistics for progressive-saccade length (PSL), incoming-saccade length (ISL), landing position (LP), skipping probability (SP), first-fixation duration (FFD), and gaze duration (GD) in
Experiments 1 and 2, as a function of target-word frequency and segmentation-preview conditions

\begin{tabular}{|c|c|c|c|c|c|c|c|c|c|}
\hline \multirow[t]{2}{*}{ DVs } & \multirow[t]{2}{*}{ Fixed effects } & \multicolumn{4}{|c|}{ Experiment 1} & \multicolumn{4}{|c|}{ Experiment 2} \\
\hline & & $b$ & $S E$ & $t$ & $p$ & $b$ & $S E$ & $t$ & $p$ \\
\hline \multirow{5}{*}{$\begin{array}{l}\text { PSL } \\
\text { (Char.) }\end{array}$} & Intercept & 4.10 & 0.17 & 23.56 & $<.001$ & 2.98 & 0.11 & 27.31 & $<.001$ \\
\hline & Word frequency & 0.39 & 0.07 & 5.94 & $<.001$ & 0.18 & 0.09 & 2.07 & .043 \\
\hline & Word segmentation & 0.36 & 0.09 & 3.97 & $<.001$ & -0.36 & 0.08 & -4.26 & $<.001$ \\
\hline & Frequency $\times$ Segmentation & 0.36 & 0.14 & 2.58 & .011 & 0.03 & 0.19 & 0.16 & .873 \\
\hline & Launch site & 0.10 & 0.04 & 2.21 & .027 & -0.07 & 0.05 & -1.37 & .170 \\
\hline \multirow{5}{*}{$\begin{array}{l}\text { ISL } \\
\text { (Char.) }\end{array}$} & Intercept & 1.64 & 0.05 & 34.51 & $<.001$ & 1.73 & 0.04 & 42.53 & $<.001$ \\
\hline & High frequency & 0.03 & 0.03 & 1.06 & .290 & 0.08 & 0.03 & 2.42 & .022 \\
\hline & Segmented preview & -0.09 & 0.03 & -3.12 & .002 & -0.17 & 0.03 & -4.77 & $<.001$ \\
\hline & High frequency $\times$ Segmented preview & 0.004 & 0.05 & 0.07 & .944 & 0.02 & 0.06 & 0.28 & .785 \\
\hline & Launch site & -0.68 & 0.03 & -26.57 & $<.001$ & -0.64 & 0.02 & -26.53 & $<.001$ \\
\hline \multirow{5}{*}{$\begin{array}{l}\text { LP } \\
\text { (Char.) }\end{array}$} & Intercept & 1.63 & 0.05 & 34.71 & $<.001$ & 1.73 & 0.04 & 42.53 & $<.001$ \\
\hline & High frequency & 0.03 & 0.03 & 1.09 & .281 & 0.08 & 0.03 & 2.42 & .022 \\
\hline & Segmented preview & -0.09 & 0.03 & -3.10 & .002 & -0.17 & 0.03 & -4.77 & $<.001$ \\
\hline & High frequency $\times$ Segmented preview & 0.02 & 0.05 & 0.34 & .735 & 0.02 & 0.06 & 0.28 & .784 \\
\hline & Launch site & 0.32 & 0.03 & 12.50 & $<.001$ & 0.36 & 0.02 & 15.07 & $<.001$ \\
\hline \multirow[t]{4}{*}{ SP } & Intercept & 0.69 & 0.19 & 3.64 & $<.001$ & -0.30 & 0.15 & -1.95 & .051 \\
\hline & High frequency & 0.47 & 0.11 & 4.18 & $<.001$ & 0.34 & 0.11 & 2.99 & .003 \\
\hline & Segmented-preview & 0.02 & 0.13 & 0.16 & .871 & -0.54 & 0.15 & -3.59 & $<.001$ \\
\hline & High frequency $\times$ Segmented preview & 0.13 & 0.21 & 0.60 & .548 & -0.02 & 0.21 & -0.10 & .920 \\
\hline \multirow{4}{*}{$\begin{array}{l}\text { FFD } \\
(\mathrm{ms})\end{array}$} & Intercept & 233.32 & 5.26 & 44.33 & $<.001$ & 262.19 & 6.25 & 41.99 & $<.001$ \\
\hline & High frequency & -12.45 & 4.19 & -2.98 & .004 & -14.70 & 3.72 & -3.95 & $<.001$ \\
\hline & Segmented preview & -20.21 & 3.80 & -5.32 & $<.001$ & -13.62 & 3.99 & -3.41 & .002 \\
\hline & High frequency $\times$ Segmented preview & -5.32 & 7.28 & -0.73 & .467 & 7.08 & 7.61 & 0.93 & .358 \\
\hline \multirow{4}{*}{$\begin{array}{l}\text { GD } \\
(\mathrm{ms})\end{array}$} & Intercept & 238.43 & 6.16 & 38.72 & $<.001$ & 277.29 & 7.15 & 38.79 & $<.001$ \\
\hline & High frequency & -12.95 & 4.71 & -2.75 & .008 & -20.59 & 4.69 & -4.39 & $<.001$ \\
\hline & Segmented preview & -21.33 & 3.94 & -5.41 & $<.001$ & -25.49 & 5.53 & -4.61 & $<.001$ \\
\hline & High frequency $\times$ Segmented preview & -9.46 & 7.89 & -1.20 & .234 & 7.74 & 9.39 & 0.83 & .414 \\
\hline
\end{tabular}

frequency to modulate saccade length, as predicted by dynamicadjustment accounts of saccade targeting (e.g., Y. Liu et al., 2015, 2016). The second was for the presence of word boundaries to drive the eyes toward the centers of target words, as predicted by default-targeting accounts (Yan et al., 2010; see also Engbert et al., 2005; Reichle et al., 2012). These findings suggest that a more integrative account of saccadic targeting during reading is required, as will be discussed next.

\section{General discussion}

This article reported two eye-movement experiments examining how parafoveal word frequency and segmentation influence saccade targeting during Chinese reading. The three key findings from these experiments can be readily summarized as follows: First, high-frequency words and words demarcated by word boundaries were easier to process as evidenced by shorter first-fixation and gaze durations on those words. Second, saccades tended to move the eyes further into the parafovea when they contained high-frequency as compared with low-frequency words. And finally, although the provision of clear boundary information facilitated lexical processing, it did not result in lengthened saccades in the parafovea, but instead resulted in shorter saccades that were directed toward the centers of the target words.

This final result is consistent with previous demonstrations that the initial landing position tends to move to the left of target words that are followed by a space (see P. Liu \& Li, 2014, Tables 1 and 2; P. Liu \& Lu, 2018, Fig. 5), but is inconsistent with others showing the opposite during the reading of both Chinese (e.g., Zang, Liang, Bai, Yan, \& Liversedge, 2013) and English (e.g., Rayner et al., 1998). One possible explanation for these discrepancies is that the latter studies did not control for 


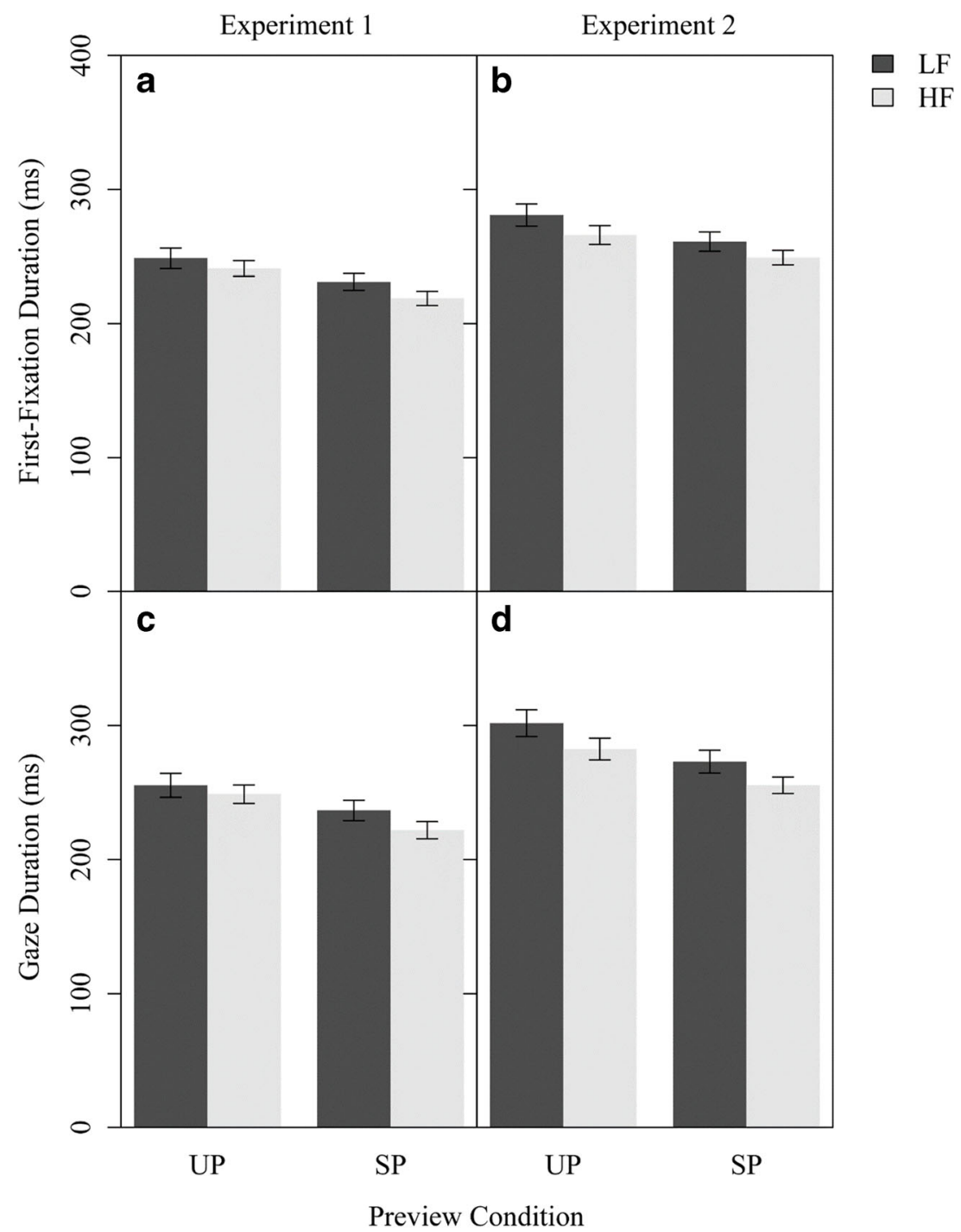

Fig. 4 Mean fixation-duration measures in Experiments 1 (left panels) and 2 (right panels). Note. HF = high frequency; LF = low frequency; UP = unsegmented preview; $\mathrm{SP}=$ segmented preview

launch site, which meant that longer saccades were likely included in their analyses - saccades that are more prone to saccadic error (McConkie, Kerr, Reddix, and Zola, 1988) and that afford less parafoveal preview (because the perceptual span only extends two to three characters to the right of fixated position; e.g., Chen \& Tang, 1998). By restricting our analyses to those saccades that were initiated from a two-character pretarget region, we avoided these potential problems by limiting our analyses to those saccades that more accurately reflect ongoing lexical processing of parafoveal words.

Although each of our aforementioned findings has been previously shown in isolation, the main novelty of our demonstrations is that aspects of both dynamic-adjustment and default-targeting are evident within the context of a single paradigm. Apart from lending direct support to early suppositions that some weighting of the two saccade-targeting mechanisms will likely be necessary to fully explain reader's eye movements (e.g., Y. Liu, Yu, et al., 2019), our findings have at least two important implications for our general understanding of eye-movement control during reading.

The first is that, in writing systems that do not normally mark word boundaries (e.g., Chinese, Thai), the "balance" between the two saccade-targeting mechanisms is likely to be very heavily weighted toward the dynamic adjustment of saccade length. The rationale for this claim is that, in the absence of clear word-boundary information, the other factors that have been shown to influence where the eyes move via modulating saccade length (e.g., word frequency) can exert their full effect.

The second implication of our findings for an understanding of eye-movement control is the converse - that even the occasional introduction of word-boundary information can have a rapid and marked effect on where a reader's eye will move, even overriding the overlearned propensity to move the eyes using information about ongoing lexical-processing 
difficulty. This suggests that, in languages like English and German where word boundaries are clearly delineated, the "balance" between the two saccade-targeting mechanisms is likely to be very heavily weighted toward the use of default saccade targets, as posited, for example, by current models of eye-movement control in reading (e.g., E-Z Reader: Reichle et al., 2012; SWIFT: Engbert et al., 2005).

Finally, in relation to the latter models, we again note that, because they were developed to explain eye movements during the reading of spaced, alphabetic writing systems, the models incorporate strong versions of the default-targeting hypothesis - that saccades are directed toward the centers of upcoming words or, in the case where those words are to be skipped, the centers of the next words. For that reason, the models should not be able to explain the findings that saccades exiting high-frequency words tend to be longer than those exiting low-frequency words (Rayner et al., 2004; White \& Liversedge, 2006). More importantly, to explain saccade targeting across different writing systems, it will be necessary for updated versions of these models to specify how the two saccade-targeting mechanisms are integrated and weighted to accommodate different writing systems.

Author note This research was supported by the grants from the National Natural Science Foundation of China (31500890), MOE (Ministry of Education in China) Project of Humanities and Social Sciences (18YJC190014), the Fundamental Research Funds for the Central Universities (17wkpy64), and the U.S. National Institutes of Health (RO1HD075800). All experimental materials, data, and scripts are freely available for download at https://osf.io/y84uc/.

Publisher's note Springer Nature remains neutral with regard to jurisdictional claims in published maps and institutional affiliations.

\section{References}

Chen, H., \& Tang, C. (1998). The effective visual field in reading Chinese. Reading and Writing, 10, 245-254.

Engbert, R., Nuthmann, A., Richter, E., \& Kliegl, R. (2005). SWIFT: A dynamical model of saccade generation during reading. Psychological Review, 112, 777-813.

Hyönä, J., Yan, M., \& Vainio, S. (2018). Morphological structure influences the initial landing position in words during reading Finnish. Quarterly Journal of Experimental Psychology, 71, 122-130.

Li, X., Liu, P., \& Rayner, K. (2011). Eye movement guidance in Chinese reading: Is there a preferred viewing location? Vision Research, 51, $1146-1156$

Liu, P., \& Li, X. (2014). Inserting spaces before and after words affects word processing differently in Chinese: Evidence from eye movements. British Journal of Psychology, 105, 57-68.

Liu, P., \& Lu, Q. (2018). The effects of spaces on word segmentation in Chinese reading: Evidence from eye movements. Journal of Research in Reading, 41, 329-349.

Liu, Y., Huang, R., Gao, D., \& Reichle, E. D. (2017). Further tests of a dynamic-adjustment account of saccade targeting during the reading of Chinese. Cognitive Science, 41, 1264-1287.

Liu, Y., Guo, S., Yu, L., \& Reichle, E. D. (2018). Word predictability affects saccade length in Chinese reading: An evaluation of the dynamic-adjustment model. Psychonomic Bulletin \& Review, 25, 1891-1899.

Liu, Y., Reichle, E. D., \& Li, X. (2015). Parafoveal processing affects outgoing saccade length during the reading of Chinese. Journal of Experimental Psychology: Learning, Memory and Cognition, 41, $1229-1236$.

Liu, Y., Reichle, E. D., \& Li, X. (2016). The effect of word frequency and parafoveal preview on saccade length during the reading of Chinese. Journal of Experimental Psychology: Human Perception and Performance, 42, 1008-1025.

Liu, Y., Yu, L., \& Reichle, E. D. (2019). The dynamic adjustment of saccades during Chinese reading: Evidence from eye movements and simulations. Journal of Experimental Psychology: Learning, Memory, and Cognition, 45, 535-543.

McConkie, G. W., Kerr, P. W., Reddix, M. D., \& Zola, D. (1988). Eye movement control during reading: I. The location of initial eye fixations on words. Vision Research, 28, 1107-1118.

Rayner, K. (1975). The perceptual span and peripheral cues in reading. Cognitive Psychology, 7, 65-81.

Rayner, K. (1979). Eye guidance in reading: Fixation location within words. Perception, 8, 21-30.

Rayner, K., Ashby, J., Pollatsek, A., \& Reichle, E. D. (2004). The effects of word frequency and predictability on eye movements in reading: Implications for the E-Z Reader model. Journal of Experimental Psychology: Human Perception and Performance, 30, 720-732.

Rayner, K., Fischer, M. H., \& Pollatsek, A. (1998). Unspaced text interferes with both word identification and eye movement control. Vision Research, 38, 1129-1144.

Rayner, K., \& Morrison, R. E. (1981). Eye movements and identifying words in parafoveal vision. Bulletin of the Psychonomic Society, 17, 135-138.

Reichle, E. D., Pollatsek, A., \& Rayner, K. (2012). Using E-Z Reader to simulate eye movements in non-reading tasks: A unified framework for understanding the eye-mind link. Psychological Review, 119, $155-185$.

Schilling, H. E. H., Rayner, K., \& Chumbley, J. I. (1998). Comparing naming, lexical decision, and eye fixation times: Word frequency effects and individual differences. Memory \& Cognition, 26, 1270-1281.

Tsai, J. L., \& McConkie, G. W. (2003). Where do Chinese readers send their eyes? In J. Hyönä, R. Radach, \& H. Deubel (Eds.), The mind's eye: Cognitive and applied aspects of eye movement research (pp. 159-176). Oxford: Elsevier.

Wei, W., Li, X., \& Pollatsek, A. (2013). Word properties of a fixated region affect outgoing saccade length in Chinese reading. Vision Research, 80, 1-6.

White, S. J., \& Liversedge, S. P. (2006). Foveal processing difficulty does not modulate non-foveal orthographic influences on fixation positions. Vision Research, 46, 426-437.

Yan, M., \& Kliegl, R. (2016). CarPrice versus CarpRice: Word boundary ambiguity influences saccade target selection during the reading of Chinese sentences. Journal of Experimental Psychology: Learning, Memory, and Cognition, 42, 1832-1838.

Yan, M., Kliegl, R., Richter, E. M., Nuthmann, A., \& Shu, H. (2010). Flexible saccade-target selection in Chinese reading. Quarterly Journal of Experimental Psychology, 63, 705-725.

Yu, L., \& Reichle, E. D. (2017). Chinese vs. English: Insights on cognition during reading. Trends in Cognitive Sciences, 21, 721-724.

Zang, C., Liang, F., Bai, X., Yan, G., \& Liversedge, S. P. (2013). Interword spacing and landing position effects during Chinese reading in children and adults. Journal of Experimental Psychology: Human Perception and Performance, 39, 720-734.

Zhou, W., Wang, A., Shu, H., Kliegl, R., \& Yan, M. (2018). Word segmentation by alternating colors facilitates eye guidance in Chinese reading. Memory \& Cognition, 46, 729-740. 